\title{
Socioanthropological contributions to physical therapy in chronic back pain
}

\author{
Contribuições socioantropológicas para o fazer \\ fisioterapêutico na dor crônica em coluna vertebral
}

José Alves Martins*

Universidade de São Paulo (USP), São Paulo, SP, Brazil

\begin{abstract}
Introduction: The high prevalence of chronic back pain is related to biopsychosocial factors. In this respect, pain is understood as a multifactorial phenomenon made unique by the previous ideas of each individual. Thus, the present study aimed Objective: To understand the experience of chronic back pain and the effectiveness of physiotherapeutic approaches to support new care strategies. Methods: In terms of qualitative research, a comprehensive approach was adopted using the theoretical and conceptual framework developed in the fields of anthropology and health. The sample consisted of 13 women residing in the municipality of Várzea Grande, Mato Grosso state (MT), Brazil, over 40 years old, homemakers, diagnosed with chronic back pain, treated at the Univag clinical school and who had completed physiotherapy more than six months previously. Results: Data analysis indicated that more traditional forms of outpatient physiotherapy prompted a significant improvement in chronic back pain. However, because the condition is chronic, all patients relapsed and their pain and dysfunctional conditions returned. Conclusion: Multiple factors influence the experience of chronic back pain and the constant self-management required forms a circular relationship between objective and subjective elements. On the other hand, by disregarding these elements, physiotherapeutic approaches provide predominantly technical and scientific care far removed from the experience of the affected subject. In this respect, the chronic condition requires long-term care, whereby the focus should shift from the pursuit of a cure to the care model.
\end{abstract}

Keywords: Chronic Pain. Physical Therapy Specialty. Qualitative Research.

JAM: Doctoral student, e-mail: profze-alves@usp.br 


\section{Resumo}

Introdução: A alta prevalência das dores crônicas em coluna vertebral está relacionada a fatores biopsicossociais. Nesse sentido a dor é compreendida como um fenômeno multifatorial, porém, singularizada pelos conceitos prévios de cada indivíduo. Objetivo: Compreender a experiência da dor crônica em coluna vertebral e a efetividade das abordagens fisioterapêuticas para subsidiar novas estratégias de cuidados. Métodos: No contexto da pesquisa qualitativa adotou-se a abordagem compreensiva através do referencial teórico e conceitual da fenomenologia desenvolvidos pela área da Antropologia e Saúde. A amostra foi composta por 13 mulheres, residentes no Município de Várzea Grande-MT, acima de 40 anos, trabalhadoras do lar, diagnóstico de dor crônica em coluna vertebral, atendidos na clínica escola do Univag e em alta fisioterapêutica há mais de seis meses. Resultados: A análise dos dados demonstrou que nas formas mais tradicionais a fisioterapia ambulatorial propiciou melhora significativa do quadro de dor crônica em coluna vertebral. No entanto, por se tratar de uma condição crônica, a totalidade dos pacientes recidivaram em seus quadros álgicos e disfuncionais. Conclusão: Há múltiplas influências na construção da experiência da dor crônica em coluna vertebral, admitindo uma relação circular entre elementos objetivos e subjetivos no autogerenciamento constante da mesma. Por outro lado, as abordagens fisioterapêuticas, ao desconsiderarem esses elementos, poderá instituir um cuidado predominantemente técnico-científico distante da experiência do sujeito doente. Nesse sentido a condição crônica requer um cuidado longitudinal no tempo, onde o modelo de cura deve dar lugar ao modelo de cuidado.

Palavras-chave: Dor Crônica. Fisioterapia. Pesquisa Qualitativa.

\section{Introduction}

Low back pain (LBP) that persists for more than six months is classified as a chronic condition (1). According to Maher (2), LBP is a symptom rather than a disease and affects people of all ages. Nonspecific low back pain is the most common form, when the anatomopathological cause cannot be determined. Prevalence of chronic LBP is $4.2 \%$ in people aged between 24 and 39 years and $19.6 \%$ in 20 to 59-yearolds. As such, the prevalence of chronic LBP increases linearly with age and is most common in women (3).

Chronic LBP places a significant burden on both the individual affected and society, requiring effective and priority management by the health sector (4). According to these authors, the condition is no longer viewed solely in terms of structural, anatomical or biomechanical aspects, but as a complex interplay of biopsychosocial factors, making it difficult to reliably correlate imaging and clinical findings and patient history. Clinical studies have identified a number of barriers to the use of purely evidence-based interventions (5). By contrast, in the last decade a body of quantitative research has developed that describes and interprets the subjective experiences of individuals with chronic pain (6).
Figg-Latham (7) observed poor adherence to therapeutic guidelines for lower back pain among British osteopaths, possibly reflecting a pragmatic response to healthcare market forces in clinical practice. According to the authors, the conduct of many professionals with a strong sense of professional identity is based on their attitudes, beliefs, values, motives and experiences. Concerns about the effect on professional identity of adopting rigid guidelines are not new and can also be found in other health-related professions $(8,9)$.

Pain is always subjective (10) and people learn and use it based on their individual life experiences. Griensven (11) studied the subjective aspects of experiencing chronic LBP and found that the long-term condition made patients feel trapped in the health system and despondent in the face of repeated treatment failures, resigned to a life of pain. The author reports that patient's pain and dysfunctional symptoms were invalidated when the initially enthusiastic healthcare professionals lost interest because treatment did not produce the expected results and they were unable to provide a clear explanation for the pain, leading to feelings of frustration and anxiety.

Snelgrove and Liossi (12) analyzed articles published in English between 2000 and 2012 on 
the experience of patients with chronic low back pain and described it as complex, dynamic, and multidimensional, accompanied by poor self-esteem, depression, stigma and fears about the future. The authors recommended broader therapeutic approaches based on psychology, health education, self-management strategies and support groups.

In this respect, the present study sought to understand the experience of chronic low back pain as a culturally constructed condition, in order to adopt new and more effective care strategies.

\section{Methods}

This study was conducted based on questions raised in a previous investigation (13) regarding how people understand and deal with relapses of chronic pain in their everyday lives. It was approved by the Research Ethics Committee of the Public Health School of Mato Grosso under protocol number 781.073 on September 5, 2014, and complied with all the requirements of National Health Council (CNS) Resolution 466/12. In terms of qualitative research, a comprehensive approach was adopted using the theoretical and conceptual framework of social phenomenology expressed in studies on the experience of illness in the everyday lives of individuals (14). Medical charts were selected for 76 patients diagnosed with chronic back pain and treated at the UNIVAG clinical school who had completed physiotherapy more than six months previously. The subjects were then contacted at home by telephone or in person and invited to participate in the study. Of these, 63 were excluded for reasons such as change of address, failure to provide written informed consent, cognitive difficulties, poor health, and death, among others. The final sample consisted of 13 women with an average age of 50.4 years (standard deviation 5.2), living at the same address for more than 10 years, homemakers, and residing in the municipality of Várzea Grande (MT). All the subjects had undergone treatment and been without physiotherapy for six months or more. These inclusion criteria were chosen to comply with the assumptions of this research.

The study was conducted in two stages: the first involved retrieving personal information from participant's medical charts, as well as sociodemographic data, physical and functional diagnosis and physical therapy provided. In the second stage, a semi-structured interview was conducted by a researcher with the same participants in their homes, to enable him to familiarize himself with the participants' reality. The interviews were recorded, transcribed and identified using fictitious names in order to respect the privacy of participants.

For the purpose of data analysis, thematic analysis was applied (15) to identify statements as representative and pertinent according to their characteristics and similarities. The authors report that thematic analysis is an approach aimed at extracting meaning and is widely used in phenomenologically-oriented qualitative research to identify and examine recurring patterns or themes in data, contributing to reflection and understanding of the social reality and the cultural context it belongs to.

In this respect, the present study aimed to understand the meaning attributed to back pain by the participants in order to devise and negotiate new preventive and therapeutic strategies.

\section{Results and discussion}

\section{Chronic conditions and physiotherapy treatment}

Chronic conditions are frequently labelled longterm, but the time interval is rarely specified (16). Like other health sciences, physical therapy is limited in terms of caring for chronic conditions, largely due to causal variability, high relapse rates and lack of adherence to treatment. In general, physiotherapy uses a range of assessment and therapeutic methods and resources validated by the scientific community to classify deviations as normal or pathological. Thus, the diagnosis determines the therapy through a combined process, that is, lower back pain during palpation and movement combined with positive results in predictive and imaging testing validates a diagnosis of lower back pain. This diagnosis automatically prompts the use of manual and electrotherapy resources, anti-inflammatories and analgesics in treatment. On completion of physical therapy, analgesics are combined with a variety of recommendations to prevent pain from recurring. As such, despite application of diagnostic and therapeutic resources, patients may not improve, which can translate into poor results.

Analysis of the data collected from the participants indicated that traditional forms of physiotherapy 
prompted a significant improvement in patients' pain and general condition. However, all of the patients reported back pain relapse with the same symptoms, even months after completing physical therapy.

“The pain started about 20 years ago" (...) "I've tried everything" (...) "sometimes I can't move my leg because it locks." (Rosa, 44, score of 7 on the pain scale)

"The first place I went for treatment was the rehabilitation center about 20 years ago." (Hortência, 52, score of 7 on the pain scale).

(...) "when the pain started, 25 years ago, I had to carry my kids around, bathe them, and all that movement made it worse, I got older and the pain started appearing" (Orquídea, 57, score of 9 on the pain scale)

"I've had this pain for more than 5 years; I've been in and out of physiotherapy at lots of different clinics, and it does make me feel better" (...) "when I'm lying down I feel a kind of electric shock and I know my back's going to start hurting." (Gardênia, 45, score of 5 on the pain scale)

Although the time since disease onset is relatively inaccurate in the above statements, the chronic nature of the condition is evident. Thus, it can be concluded that in the case of chronic pain, temporarily eliminating symptoms via a biomedical model is not sufficient to allow patients to resume their normal activity.

The psychosocial dimensions of illness have only recently been incorporated into physical therapy practice (17). Synnott (4) sought to develop the ability of physiotherapists to deal with the cognitive, psychological and social aspects of chronic low back pain more effectively since, according to the author, these elements are not considered when providing care. To that end, he recruited thirteen qualified physiotherapists from four countries (Belgium, Australia, Denmark and Ireland), who were specifically trained in a multidimensional patient-centered approach that recycles maladaptive movement patterns and reshapes patient's beliefs about pain, among other procedures. After the intervention, the author observed a better understanding of the nature of pain and the role of patient beliefs, as well as a new concept of the patient-professional relationship that translated into a better ability to deal with the psychosocial dimensions of chronic low back pain.

When providing care for chronic conditions, it is important for healthcare professionals to immerse themselves in the sociocultural context of patients (18) in order to better understand the unique and intersubjective dimension of the illness process and the factors that favor or hinder improvement in their overall condition. Given that a cure is not the goal in such cases, these elements can be vital to the effective management of chronic pain through a direct relationship between the physiotherapist and the patient.

In this respect, data analysis indicated that participants did not resort to a single therapy, that is, despite being submitted to treatment and having completed physiotherapy more than six months previously, they continued to exhibit symptoms similar to those that first prompted them to see a physical therapist. As such, they continue to seek additional services and professionals to alleviate their pain, as demonstrated in the statements below:

(...) "I take a lot of pain medication, but it's not very effective anymore and when the pain is really bad, I have to have an injection that's really painful" (...) "I felt better when I was doing physiotherapy at the rehabilitation center, but the pain always comes back after the treatment is over." (Orquídea, 57, score of 9 on the pain scale)

(...) "when I completed my physiotherapy sessions they recommended I continue doing it at home to stop the pain from returning. But I didn't, and the pain started again." (Orquídea, 57, score of 9 on the pain scale)

(...) “I did physiotherapy at Univag, I don't remember when! I just remember that I did my treatment there" (...) "but the pain still gets in the way a lot." (Acácia, 46, score of 9 on the pain scale)

In Portugal, Costa (19) studied pain variables in patients suffering from chronic pain and found that the impact of perceived illness was greater than that of traditional variables, such as pain intensity and pain-related incapacity, among others. The author reported that when pain is perceived as nonthreatening, patients tend to continue their 
everyday activities, which promotes functional recovery; however, pain perceived as catastrophic can trigger a vicious cycle that includes exaggerated dysfunction, fear and prolonged rest, potentially leading to more pain, incapacity and suffering.

As such, once triggered, chronic conditions require long-term care since they impact all areas of an individual's life and those affected must cope with the pain on a permanent basis.

\section{Continuous self-management and sociocultural contexts}

Unlike clinical conditions that generate acute pain and require more immediate and urgent intervention, generally in the emergency room of clinics and hospitals, the permanent nature of chronic conditions requires continuous self-management. As a rule, acute conditions occur at a time when the patient's autonomy in negotiating the care process with the health professional is compromised due to the intense pain they are experiencing. At times such as these, the patient is seeking immediate pain relief and tends to accept any therapeutic measure that will provide the expected alleviation. Thus, acute pain can hamper the affected individual's ability to reflect on and negotiate treatment measures, which are urgent in these cases.

El-Haddad (20) investigated the experiences of patients with acute back pain hospitalized in Australia and found that they were forced to navigate a healthcare system they did not understand in pursuit of recovery. Physically incapacitated, they felt powerless to communicate because the combination of acute pain and opioid analgesics affected their judgment and memory of events, preventing the patients from communicating their experience of the condition and prompting them to leave all the clinical decisions in the hands of health professionals.

By contrast, chronic pain is typically less intense but persistent, allowing those affected to continue their everyday routine and live with the condition, preserving their autonomy to manage their illness, including deciding whether or not to adhere to the prescribed treatment. In this scenario, it is generally the patient and not the physiotherapist who makes the decisions in addressing and coping with back pain. To that end, they draw on elements from their own sociocultural context to give meaning to their condition, as illustrated below:
(...) "now I do things slowly and only when I can. Like today, I'm washing clothes! I've already taken a painkiller because I know I'll be in pain overnight. So, to avoid feeling too much pain, I only wash clothes twice a week" (...) "I only do the housework because there's noone else to do it" (...) "some days I can't bear to clean the house so I go grocery shopping, visit family and friends, work; I do it despite the pain, I don't give in to the pain." (Orquídea, 57, score of 9 on the pain scale)

(...) "I turned to prayer for help" (...) "often I would go to church in a lot of pain, the priest would put his hands on me and pray and the pain would disappear immediately; even over the phone they would pray and the pain disappeared. I realized that some pain is spiritual and that my problems with pain increased after I lost my husband." (Rosa, 44, score of 7 on the pain scale).

This highlights the need to understand the experience of chronic pain as a culturally constructed concept interpreted differently in each social group, with meanings that are created and shared, varying over time. Igwesi-Chidobe (21) explored the experiences of people living with nonspecific chronic low back pain in a Nigerian community and found that chronic back pain is not considered an illness in that culture, but is described according to beliefs related to manual labor, degeneration, spiritual and cultural beliefs, with a significant difference between urban and rural contexts.

These beliefs translated into dissatisfaction with official healthcare and the adoption of strategies that facilitated or compromised recovery. As such, it can be concluded that each culture has its own language to represent chronic pain.

$\mathrm{Fu}(22)$ investigated the influence of the patientprofessional relationship on the self-management of chronic back pain in Northern England and concluded that patients should be encouraged to take an active role in the self-management of chronic back pain and their functional problems. In chronic conditions, patients have complete autonomy to continue their everyday routine, either damaging or protecting their back. This is part of their social context and physiotherapists should not disregard this knowledge. These patients are immersed in representations, symbols and meanings from their own sociocultural universe that form the 
perceptive foundation that gives meaning to their pain and injuries and will determine their unique forms of self-management, as demonstrated in the statements below:

(....) "so I started doing physiotherapy and I felt really good, I even missed it. I was really pleased, I really like the physiotherapists and they taught me lots of exercises. But I didn't continue with the exercises at home, so the pain in my back returned; it was really painful" (...) "when it's really bad, I remember the exercises I did and I start doing them again at home, and I feel better." (Hortência, 52, score of 7 on the pain scale)

"The physiotherapist told me all sorts of things I shouldn't do: washing clothes, cleaning the house, lifting heavy things. I almost never lift heavy things, but I wash clothes all the time and clean the house, but then later in the day the pain is terrible." (Hortência, 52, score of 7 on the pain scale).

Thus, far from the sociocultural contexts that trigger attitudes and behaviors harmful to the back, and unaware of the habits, customs, meanings and representations that give meaning to forms of taking care (or not) of the spine, physiotherapists prescribe inappropriate treatments, potentially resulting in patients' failure to comply with recommendations and suspending or withdrawing from therapy. These influences can lead to poor adherence and a decline in treatment success, as observed in the present study. These dimensions were repeatedly referred to by participants in this study:

(...) "some days my pain is better and sometimes it's worse; I've realized that it depends a lot on my emotional state, when I'm anxious or irritated my pain is worse, but I don't let that stop me from doing anything; the only difference is that when I'm in pain I do everything more slowly." (Rosa, 44, score of 7 on the pain scale).

"I take painkillers and sometimes they help, but not always. I drink tea, but not much; it's mainly medicine that I take for pain relief, and it does help a little. I also stopped doing a lot of things; I used to wash clothes a lot, but I can't anymore." (Margarida, 49 , score of 10 on the pain scale).
(...) "but when my back hurts the pain is really bad, it's a burning sensation that affects my whole spine, but I don't take any medication or do any exercises for it" (...) "I've been told to do different exercises at home, but I never have, I'm really lazy about it." (Tulipa, 54, score of 10 on the pain scale)

These statements reaffirm the power of the social world over people, demonstrating that healthcare knowledge should move beyond rationalscientific guidelines and seek new strategies aimed at incorporating sociocultural contexts into therapeutic recommendations.

Physiotherapy guidelines and recommendations based on the concept of health risk

Physiotherapy treatment based primarily on resources to eliminate pain was a recurring theme in this study, with patients given recommendations on how to "behave" at home after completing physical therapy (using the correct posture when sitting, sleeping, washing or ironing clothes, lifting heavy items, as well as continuing the exercises taught at the teaching clinic).

Recommendations regarding healthy postural habits include warnings about the risk of pain returning should these not be followed. This allows physiotherapists to feel morally comforted by the knowledge that they are complying with most of the clinical protocols validated by physiotherapeutic science.

However, greater reflection is suggested in this case. Healthcare practices occur in the encounter between patient and professional, when both individuals can suggest possibilities capable of improving lives or causing more suffering. If a homemaker avoids all the risks to her back in line with physiotherapy recommendations, she will no longer be able to perform household chores and loses her personal and social identity. In this hypothetical case, the physiotherapist causes sadness, further exacerbating her difficult situation. A variety of habitual postures and movements pose a risk to the spine, making this risk a normal part of a person's existence. In this respect, discourse on the pathologization of risk is in line with scientific reasoning. Many practices based on the sophistry 
of scientific models prescribe the "ideal behavior" for individuals suffering from high blood pressure, diabetes, mental disorders, and chronic pain, among others. When these recommendations are not adhered to, blame falls on the patient, invalidating their condition when in fact it is the prescribed treatment that is not socially acceptable.

In New Zealand, Darlow (23) analyzed attitudes and beliefs in people with back pain in terms of their motivation to engage in physical activity and revealed that their motivations were psychological in nature rather than social or physical. As such, the interpretation of pain in that culture depends on its context and duration in association with the type of physical activity. A study by Cedraschi (24) found that somatic symptoms can be perceived as personal weakness and are associated with stigmatization, invalidating the symptoms of the patient who must first prove that their pain exists. The combination of chronic symptoms and their lack of specificity can make health professionals more skeptical of chronic conditions. In a study by Cummings (25), the experience of chronic back pain was characterized by a feeling of social isolation and the paradoxical need to trust others despite their own autonomy.

MacNeela (5) conducted an ethnographic metaanalysis of studies that addressed the experience of chronic back pain and identified the need to examine the trajectory of the condition and the social identity of those affected. The author highlighted unsatisfactory relationships between patients and healthcare professionals in that they propose interventions based on multidisciplinary approaches, with engagement centered on the individual and awareness of biopsychosocial domains.

The disease is not fragmented, and risks, which are considered part of the condition, are permeated by the unique features of the patient's life. Thus, risks and suffering cannot be completely eliminated using interventionist methods. In this respect, risk is part of life and the "health-oriented authority" of the rational scientific model and its intervention techniques can mistakenly "normalize behavior".

Physiotherapy and healthcare models

This study did not collect and analyze data on physiotherapy treatment in primary healthcare; however, the information gathered at the secondary and tertiary levels made it possible to reflect on the first level of healthcare. At less than half a century old, physiotherapy is one of the youngest fields in the health sector and despite significant advances, scientific research in the area is still incipient. The origins of physical therapy lie in tertiary care aimed primarily at cure and rehabilitation, making hospitals and outpatient clinics its primary treatment settings. These facilities prioritize short-term approaches and remove patients from their own contexts in order to seek treatment. Lack of knowledge regarding the patient's reality hampers the ability to provide comprehensive care and compromises the patienthealth professional relationship, since it prevents the physiotherapist from obtaining a broader understanding of the illness process.

Physical therapists focus almost entirely on curing ailments and rehabilitating the injured. However, the novel epidemiological scenario in Brazil and the new organizational framework of the health system suggest the need to restructure the professional practices and range of activities of physiotherapists. This restructuring process involves bringing physical therapists under the umbrella of primary healthcare $(26,27)$, with activities aimed at long-term care and immersion in the universe of patients. The World Health Organization has moved away from the anatomicalclinical approach to chronic low back pain toward a biopsychosocial model that attributes pain to complex interactions between anatomical, psychological, social and occupational factors (28). Morales-Asencio (29) studied chronic diseases in relation to conventional healthcare services in Spain and found significant consequences of flaws in these care models, such as preventable hospitalization, lack of continuous care and unsatisfactory outcomes for patients.

In the field of healthcare, there is growing interest in strengthening patient participation in decisions regarding their care (30). With respect to homemakers (the targets of this study) and taking care of the spine, factors that trigger pain are part of their everyday lives in the home. The availability of a physiotherapist nearby, with regular home visits, could ensure the bonds needed for long-term care, characterized by physiotherapy treatment that is discussed and consistent with the sociocultural diversity of these individuals, promoting greater adherence and success. 


\section{Conclusion}

The data collected indicate a circular relationship between objective, subjective, material and symbolic elements of self-management in chronic low back pain (LBP). To a certain extent, these elements may determine adherence to postural recommendations and the success of physiotherapy treatment. Prioritizing the psychosocial dimension of chronic LBP gives greater visibility to this often-neglected factor in traditional physiotherapy approaches, which contrast with the comprehensive approach based on the sociocultural context of these patients. As such, this study found that on completion of physiotherapy, the treatment successfully reduced painful and functional complications and alleviated symptoms; however, the same symptoms resurfaced after six months or more without physical therapy. In this respect, the present study does not discuss technical and scientific evidence regarding physiotherapy, but suggests a new way of thinking about care models for chronic back pain.

The health sector is currently dominated by clinical protocols, guidelines, managed care and clinical management, that is, evidence-based practices that legitimize health knowledge. Despite the importance of these strategies, particularly in high-tech procedures, when taken to the extreme they result in significant losses when administrative decisions are favored over clinical ones, that is, the experts who devise the protocols and are far removed from the lives of patients ultimately make decisions about treatment. Thus, healthcare activities are preceded by previously constructed and validated techniques even before the physiotherapist sees the patient, as if life always obeys the discourse of science.

In general, healthcare should stem from an encounter that is free from impositions, whereby physiotherapists can be influenced by the unique characteristics of each patient and work alongside them to provide single forms of care. In short, learning from the patients themselves about their experience of chronic pain can contribute to devising alternative forms of care and greater success in physiotherapy treatment.

\section{References}

1. Braga $A B$, Rodrigues CMA, Lima GVMP, Melo LR, Carvalho AR, Bertolini GRF. Comparação do equilíbrio postural estático entre sujeitos saudáveis e lombálgicos. Acta Ortop Bras. 2012;20(4): 210-12.

2. Maher C, Underwood M, Buchbinder R. Non-specific low back pain. Lancet 2017;389(10070):736-47.

3. Meucci RD, Fassa AG, Faria NMX. Prevalence of chronic low back pain: systematic review. Rev Saúde Pública. 2015;49(73):1-10.

4. Synnott A, O'Keeffe M, Bunzli S, Dankaerts W, O'Sullivan P, Robinson K, et al. Physiotherapists report improved understanding of and attitude toward the cognitive, psychological and social dimensions of chronic low back pain after Cognitive Functional Therapy training: a qualitative study. J Physiother. 2016;62(4):215-21.

5. MacNeela P, Doyle C, O'Gorman D, Ruane N, McGuire BE. Experiences of chronic low back pain: a metaethnography of qualitative research. Health Psychol Rev. 2015;9(1):63-82.

6. Kress HG, Aldington D, Alon E, Coaccioli S, Collett B, Coluzzi F, et al. A holistic approach to chronic pain management that involves all stakeholders: change is needed. Curr Med Res Opin. 2015;31(9):1743-54.

7. Figg-Latham J, Rajendran D. Quiet dissent: The attitudes, beliefs and behaviours of UK osteopaths who reject low back pain guidance - A qualitative study. Musculoskelet Sci Pract. 2016;27: 97-105.

8. Gomes R, Lima VV, Oliveira JM, Schiesari LMC, Soeiro E, Damázio LF, et al. A Polissemia da governança clínica: uma revisão da literatura. Ciência Saúde Coletiva. 2015; 20(8):2431-9.

9. Lin KY. Physicians'perceptions of autonomy across practice types: Is autonomy in solo practice a myth? Soc Sci Med. 2014;0:21-9.

10. Sallum AMC, Garcia DM, Sanches M. Dor aguda e crônica: revisão narrativa da literatura. Acta Paul Enferm. 2012;25(1):150-4. 
11. Griensven HV. Patients' experiences of living with persistent back pain. Int J Osteopath Med. 2016;19:44-9.

12. Snelgrove S, Liossi C. Living with chronic low back pain: a metasynthesis of qualitative research. Chronic Illn. 2013;9(4):283-301.

13. Martins JA, Rodrigues HR, Silva JB, Lima JO. A fisioterapia no cotidiano de mulheres com dores na coluna vertebral: em busca da resolutividade. Anais do XXIV Fórum Nacional de Ensino em Fisioterapia e I Congresso Brasileiro de Educação em Fisioterapia; 24-27 de Setembro 2014; Natal-RN, Brasil. Natal; Abenfisio; 2014.

14. Castro FF. A sociologia fenomenológica de Alfred Schutz. Ciências Sociais Unisinos. 2012;48(1):52-60.

15. Javadi M, Zarea K. Understanding Thematic Analysis and its Pitfall. J Clie Care. 2016;1(1):33-39.

16. Lerum SV, Solbraekke KN, Holmoy T, Frich JC. Unstable terminality: negotiating the meaning of chronicity and terminality in motor neurone disease. Sociol Health Illn. 2015;37(1):81-96.

17. Caetano VC, Cruz DT, Silva GA, Leite ICG. O lugar ocupado pela assistência fisioterapêutica: representações sociais de trabalhadores com DORT. Fisioter Mov. 2012;25(4):767-76.

18. Rutledge DN, Cantero PJ, Ruiz JE. Chronic pain management strategies used by low income overweight Latinos. Chronic Illn. 2013;9(2):133-44.

19. 1Costa ECV, Valea S, Sobrala M, Pereira MG. Illness perceptions are the main predictors of depression and anxiety symptoms in patients with chronic pain. Psychol Health Med. 2015:1-13.

20. El-Haddad C, Damodaran A, McNeil HP, Hu W. The experience of patients admitted to hospital with acute low back pain: a qualitative study. International Journal of Rheumatic Diseases. 2016 [cited 2016 Apr 29]. Available from: https://tinyurl.com/mc3letq

21. Igwesi-Chidobe CN, Kitchen S, Sorinola IO, Godfrey EL. "A life of living death": the experiences of people living with chronic low back pain in rural Nigeria. Disabil Rehabil. 2017;39(8):779-90.

22. Fu Y, McNichol E, Marczewski K, Closs SJ. Exploring the influence of patient-professional partnerships on the self-management of chronic back pain: A Qualitative Study. Pain Manag Nurs. 2016;17(5):339-49.
23. Darlow B, Perry M, Dean S, Mathieson F, Baxter GD, Dowell A. Putting physical activity while experiencing low back pain in context: balancing the risks and benefits. Arch Phys Med Rehabil. 2016;97(2):245-51.

24. Cedraschi C, Luthy C, Girard E, Piguet V, Desmeules J, Allaz AF. Representations of symptom history in women with fibromyalgia vs chronic low back pain: a qualitative study. Pain Med. 2012;13(12):1562-70.

25. Cummings EC, Schalkwyk GIV, Grunschel BDG, Snyder MK, Davidson L. Self-efficacy and paradoxical dependence in chronic back pain: A qualitative analysis. 2016 [cited 2017 Jan 24]. Available from: https://tinyurl.com/mc3letq

26. Belettini NP, Rodrigues F, Cruz TS, Ferreira KC, Tuon L, Coelho BLP. Fisioterapeutas integrantes do Núcleo de Apoio à Saúde da Família do Estado de Santa Catarina: competências e desafios. Fisioter Bras. 2013;14(6):433-8.

27. Fernandes JM, Rios TA, Sanches VS, Santos MLM. NASF's tools and practices in health of physical therapists. Fisioter Mov. 2016;29(4):741-50.

28. Bailly F, Foltza V, Rozenberga S, Fautrela B, Gosseca L. The impact of chronic low back pain is partly related to loss of social role: A qualitative study. Joint Bone Spine. 2015;82(6):437-41.

29. Morales-Asencio JM, Martin-Santos FJ, Kaknani S, Morilla-Herrera JC, Fernández-Gallego MC, GarcíaMayor S, et al. Living with chronicity and complexity: Lessons for redesigning case management from patients' life stories - A qualitative study. J Eval Clin Pract. 2016;22(1):122-32.

30. Stennera R, Swinkelsb A, Mitchellb T, Palmer S. Exercise prescription for patients with non-specific chronic low back pain: a qualitative exploration of decision making in physiotherapy practice. Physiotherapy; 2016;102(4):332-8.

Received in $02 / 13 / 2016$

Recebido em 13/02/2016

Approved in 04/18/2017

Aprovado em 18/04/2017 